\title{
Elaboración metafórica en una intervención narrativo- conversacional de tratamiento del uso de drogas
}

\section{Metaphoric Elaboration in a Narrative-Conversational Intervention for Drug Abuse Treatment}

\author{
Sara Elisa Gracia-Gutiérrez de Velasco, David Bruno Díaz-Negrete, \& Carmen Fernández-Cáceres \\ Centros de Integración Juvenil, Ciudad de México, México
}

\begin{abstract}
Resumen: En el presente trabajo se describe el proceso elaborativo suscitado a partir de una intervención narrativo-conversacional breve, dirigida a reforzar el tratamiento y la reintegración social de personas con uso problemático de drogas. La intervención comprendió tres sesiones centradas en la reconstrucción de la experiencia en tratamiento y de las expectativas respecto de la próxima reintegración social, a partir de un ejercicio narrativo basado en una metáfora del tratamiento como viaje. Participaron 10 personas captadas en dos unidades de tratamiento en Ciudad de México. El ejercicio de una escucha activa propició la integración cognitivo-afectiva de la experiencia en el tratamiento, así como el esclarecimiento de expectativas, temores o deseos suscitados por el próximo término del mismo. Se observó una abundante producción metafórica, vinculada con nuevas formas de significar la experiencia, una amplia expresión de afectos y una mayor claridad ante el futuro.
\end{abstract}

Palabras clave: terapia narrativa, terapia conversacional, abuso de drogas, metáfora, proceso elaborativo.
Abstract: This paper describes the elaborative process drawn from the implementation of a brief narrative-conversational intervention, aimed at reinforcing treatment and social reintegration of people with drug abuse problems. The intervention comprised three sessions focused on a dialogical reconstruction of the experience in treatment and expectations about social reintegration, by means of a narrative exercise based on the metaphor of treatment as a journey. A sample of 10 participants was recruited from two treatment units in Mexico City. Active listening led to a greater cognitive-affective integration of treatment experience, as well as to clearing up expectations, fears and desires caused by the upcoming end of treatment. An ample metaphorical production was observed, which was linked to new ways of signifying experience, a wide expression of affections, and a clearer picture of the future.

Keywords: narrative therapy, conversational therapy, drug abuse, metaphor, elaborative process.

Contacto: S. Gracia-Gutiérrez de Velasco. Tlaxcala 208, col. Hipódromo, delegación Cuauhtémoc, C.P. 06100, México, Distrito Federal. Correo electrónico: sara.gracia@cij.gob.mx

Cómo citar: Gracia-Gutiérrez de Velasco, S. E., Díaz-Negrete, D. B., \& Fernández-Cáceres, C. (2015). Elaboración metafórica en una intervención narrativo-conversacional de tratamiento del uso de drogas. Revista de Psicología, 24(2), 1-18.

http://dx.doi.org/10.5354/0719-0581.2015.38005 


\section{Introducción}

Se describe en este trabajo el proceso elaborativo generado por la aplicación de una intervención narrativo-conversacional dirigida al tratamiento del consumo problemático de drogas, basada en tres atributos principales: la colaboración dialógica entre terapeuta y consultante; la importancia de la elaboración narrativa en la integración psicológica de la experiencia y la posibilidad de incidir en la deconstrucción de discursos dominantes (Díaz-Negrete, Gracia-Gutiérrez de Velasco, \& Fernández-Cáceres, 2015).

En apego a la idea de colaboración, se adoptó como primera característica de la presente propuesta el establecimiento de un diálogo horizontal, no directivo, entre terapeuta y consultante (Anderson, 1997; Anderson \& Goolishian, 1992), brindando acogida y continente al ejercicio narrativo como instancia para la consolidación del proceso y la alianza terapéutica (Angus \& McLeod, 2004; von Braun, Larsson, \& Sjöblom, 2013).

La colaboración dialógica exige reconocer que los saberes locales, propios de la cotidianidad y de la experiencia personal, son tan relevantes como los especializados (Kvale, 1999; White \& Epston, 1993), por lo que el terapeuta debe colocarse en una posición de no saber y de escucha activa, la cual implica curiosidad y un legítimo interés por el saber y la experiencia del consultante, ofreciéndole un acompañamiento aceptante y respetuoso (Anderson, 1997, 2001, 2005; Shotter, 2005). Más aun, según White (2002) el terapeuta tendría que situarse a la zaga y nunca por delante del consultante.

En segundo lugar, se asumió que la experiencia está narrativamente estructurada y que las estructuras narrativas confieren coherencia y sentido a la existencia (Bruner, 1996; Hänninen \& Koski-Jännes, 2004; McLean \& Fournier, 2008; Singer, Singer, \& Berry, 2013). De ello se sigue que la intervención terapéutica ha de estimular el "razonamiento autobiográfico" y la reelaboración cognitivo-afectiva de la experiencia (Angus \& Bouffard-Bowes, 2003; Hardtke \& Angus, 2004; McLean, 2008; McLean \& Fournier, 2008; McLean, Pasupathi, \& Pals, 2007; Singer \& Bluck, 2001; Singer et al., 2013; entre otros). Según Angus y McLeod (2004), la narración conforma el proceso terapéutico mismo.

Por el contrario, la cristalización de esquemas narrativos rígidos resulta en la reproducción de estereotipos que eclipsan la singularidad de la persona, saturados de implicaciones negativas y pobres en significado (Singer et al., 2013; White \& Epston, 1993). De acuerdo con esto, se planteó fortalecer la capacidad de elaboración narrativa y (re)significación de los consultantes entendiendo que, así como los problemas se construyen en el lenguaje, lo mismo ocurre con su resolución (Anderson, 1997; Anderson \& Goolishian, 1992).

Por lo que se refiere al proceso elaborativo, se ha señalado (Singer \& Bluck, 2001; Singer et al., 2013) que el esfuerzo por conferir continuidad y coherencia a la experiencia comprende dos componentes: 1) la confección del relato propiamente dicha, es decir, la creación de unidades de pensamiento a partir de imágenes, argumentos, secuencias, personajes y otros elementos narrativos; y 2) el razonamiento autobiográfico que apunta a la interpretación reflexiva de los contenidos de la experiencia. Este incluye el establecimiento de conexiones entre acontecimientos y entre estos y la esfera del yo, así como la evaluación afectiva de estas co- 
nexiones en un esfuerzo orientado a conferir coherencia temática a la experiencia (McLean, 2008; McLean \& Fournier, 2008). En coincidencia, Angus y colaboradores (Angus \& Bouffard-Bowes, 2003; Angus \& Hardtke, 1994; Hardtke \& Angus, 2004) sostienen que el procedimiento terapéutico comprende un proceso externo de reestructuración de episodios, uno interno de identificación de afectos y uno reflexivo, de articulación de un nuevo sentido biográfico global.

Un componente importante de este proceso elaborativo es la metáfora, es decir, el desplazamiento del sentido propio de una expresión o de un término por un sentido figurado, a partir de una relación de homología o semejanza. La metáfora representa un recurso expresivo de uso común que facilita la comprensión de una cosa en términos de otra, tanto en la vida cotidiana (Lakoff \& Johnson, 1995) como en el ámbito terapéutico (Wirtztum, van der Hart, \& Friedman, 1988). La metáfora favorece la expresión sintética y significativa de afectos y sucesos que no habrían podido ser expresados de otra manera, promoviendo el insight y la (re)significación de la experiencia (Sarbin, 1986; Shinebourne \& Smith, 2010). Desde un punto de vista discursivo, la metáfora implica una enunciación que trastoca las reglas de la lógica, dando lugar a una expresión que exige dilucidación y esclarecimiento y que está, por tanto, vinculada con la producción de nuevos significados (Ricoeur, 2003).

En tercer lugar, la conversación terapéutica permite deconstruir las condiciones naturalizadas que subyacen en la reproducción de los problemas, con el fin de remitirlas a sus condicionantes subjetivos y sociales (Brown, 2007). Se trata de promover una mayor flexibilidad y sensibilidad a la polifonía del relato, así como la autonomía y capacidad crítica del con- sultante para sustraerse de categorías discursivas dominantes (Angus \& Hardtke, 2007; Angus \& McLeod, 2004; McLean \& Fournier, 2008; Singer \& Rexhaj, 2006; White, 2002). A partir de este ejercicio deconstructivo y del principio de aceptación incondicional del otro, la propuesta aquí descrita implica una dimensión ética e incluso política fundamental, dada la posibilidad de visibilizar e incluso superar formas de subordinación instituidas, abriendo la elaboración narrativa a la contingencia e incertidumbre propias de la existencia (Diamond, 2002; Sanders, 2007; White, 2002).

El derrotero ético y político de la intervención supone una actitud vigilante contra la reproducción de jerarquías y sometimientos en el contexto de la terapia; en el caso del consumo de sustancias, exige someter a una revisión constante los discursos hegemónicos, desplegando otras miradas respecto del problema (Brown, 2007; Sanders, 1998; White \& Epston, 1993).

Una última particularidad de esta perspectiva es el dar cabida a un componente prospectivo dirigido al esclarecimiento de expectativas, deseos y temores asociados con el futuro inmediato, permitiendo la proyección del relato en una realización progresiva de propósitos (Gergen, 2007; Gergen \& Gergen, 1986). De igual manera, se centra antes en las consecuencias de los problemas, que en sus causas u orígenes.

Con esta propuesta se persigue ofrecer una alternativa de abordaje del consumo de drogas, en un campo en el que se ha tendido a privilegiar la aplicación de intervenciones estructuradas y estandarizadas que, con frecuencia, inducen la normalización de las conductas y se enfocan en el control del consumo, sin dejar espacio a la problemática subjetiva y social subyacente. 


\section{Método}

El propósito de este trabajo fue ilustrar el proceso de elaboración narrativa y metafórica resultante de la aplicación de una intervención narrativo-conversacional breve con personas en tratamiento por consumo problemático de drogas en Centros de Integración Juvenil (CIJ), organización mexicana dedicada a la atención del uso de sustancias. Con este objetivo se presenta un esbozo general del contenido de las sesiones efectuadas con 10 consultantes, así como la descripción de un caso particular. El supuesto es que dada la deprivación psicosocial que con frecuencia afecta a las personas con problemas de drogas, ofrecerles un espacio basado en la aceptación y la escucha respetuosa puede representar una oportunidad para el despliegue de un proceso reflexivo capaz de promover una integración significativa de la experiencia, remover categorías y etiquetas que tienden a obstaculizar el cambio y, finalmente, fortalecer su capacidad para encarar la próxima reintegración social.

\section{Participantes}

Participaron ocho hombres y dos mujeres de entre 16 y 38 años, en su mayoría con estudios de bachillerato; cuatro eran solteros y seis vivían en pareja. Dos estudiaban, una se ocupaba del hogar y siete contaban con un empleo remunerado. La mayoría señaló a la marihuana y a la cocaína-crack como droga de mayor impacto.

Los 10 se encontraban entre la décima y décimo segunda semanas de tratamiento hospitalario (cinco hombres) o en consulta externa (dos mujeres y tres hombres). El programa en el que participaban comprendía un abordaje interdisciplinario y ecléctico, que incluía terapia individual, familiar y grupal, actividades psicoeduca- tivas, orientación a familiares y farmacoterapia en los casos que lo requerían.

\section{Descripción de la intervención}

La intervención comprendió una serie de tres sesiones con enfoque narrativoconversacional de 60 a 90 minutos, centradas en el recuento narrativo de la experiencia de los consultantes en el tratamiento, y en el esclarecimiento de sus expectativas de reintegración social. El intercambio conversacional se basó en la introducción de la metáfora del tratamiento como viaje, a través de preguntas acerca del inicio como partida, el proceso como trayecto y la reinserción al medio de procedencia como próximo arribo. La metáfora del viaje tiene un arraigado sustrato cultural (Lakoff \& Johnson, 1995; Mikkonen, 2007; Smelser, 2009) y ha sido aplicada al proceso de tratamiento en general y en el abordaje del consumo de drogas en particular (Epston \& White, 1992; Hegarty, Smith, \& Hammersley, 2010; Shinebourne \& Smith, 2010; Tay, 2011). Al término de las sesiones se elaboró una carta que reconstruía aspectos significativos del proceso recuperando la voz de los consultantes (White, 2002, 2007; White \& Epston, 1993), la cual les fue entregada como elemento de cierre.

El objetivo de la intervención fue ofrecer a los consultantes un espacio de diálogo y escucha para propiciar la integración cognitivo-afectiva de su experiencia en tratamiento, así como esclarecer expectativas, temores y deseos, suscitados por el egreso y la reintegración social.

La conducción de las sesiones estuvo a cargo de la primera autora de este trabajo, quien guio su quehacer de acuerdo con los siguientes parámetros: 
Ejercer una escucha activa. Implicó concentrarse en el decir del consultante, frenando el propio flujo asociativo para dejarse envolver por el relato, a través de un intercambio guiado por el contenido de este.

Situarse como "no experta". Sin obviar la asimetría inherente al encuentro terapéutico, se propició la horizontalidad de la relación, procurando mantener un genuino interés por el saber del consultante y tratando de comprender a cada momento el significado que le atribuyera a los episodios relatados, sin intentar analizarlos según los códigos del saber psicológico.

Dar estructura al diálogo. El diálogo se estableció de manera abierta y no directiva; las preguntas apuntaron principalmente a ampliar algún segmento del relato, aclarar dudas o indagar el sentido atribuido a las cosas, desde un plano inmanente a la propia narración. Tuvieron, así, un carácter tentativo, exploratorio y no determinativo, evitando dirigir el flujo de ideas del consultante.

$\sim$ Cuidar el bienestar del consultante. En todo momento se buscó preservar la seguridad psicológica y la confianza. Siempre que fue preciso, se concedió el tiempo necesario para ventilar afectos, inquietudes y preocupaciones, hasta el restablecimiento de un tono afectivo equilibrado.

Modular el desarrollo de las sesiones. El proceso se desplegó mediante un trabajo secuencial y paulatino, espaciado temáticamente de acuerdo con los tres momentos del tratamiento articulados según la metáfora del viaje.

$\sim$ Lo que se evitó. La terapeuta se abstuvo de brindar consejos, hacer interpretaciones, connotar o emitir juicio alguno, reduciendo al mínimo sus intervenciones.

Para entablar el diálogo se recurrió a una serie de preguntas. En la fase de la partida (inicio del tratamiento), estas aludían a la decisión de emprender el viaje; otras intentaban estimular un mayor despliegue metafórico en torno al sentido de la búsqueda de tratamiento, a saber: "¿Cuál era tu situación cuando decidiste iniciar el viaje?", "QQué personas estaban cerca de ti?”, “QQué ocurría en el lugar del que partiste que no encajaba con tu vida?", "¿Qué cosas decidiste traer contigo?", "¿Qué de lo que dejaste quisieras volver a encontrar a tu regreso?".

En la segunda etapa las preguntas se formularon en términos de: "¿Cómo ha sido para ti este viaje?", "¿Qué has aprendido en el trayecto?", "¿Quiénes te han acompañado en la travesía?”, “¿Quiénes se quedaron atrás y qué sientes al respecto?”, “Cómo has cambiado a lo largo del viaje?", "¿Qué temores te han asaltado en el trayecto?”, ¿QQué has traído contigo?”.

En la última fase se plantearon interrogantes como estas: "¿Cómo te sientes ahora, ya próximo al final del viaje?", "¿Hay cosas que te preocupan a tu arribo?”, “CCómo podrías estar mejor preparado(a) para el regreso?”, “Cuáles son tus expectativas al llegar?”, “Qué piensas hacer a la hora del arribo a destino?". El propósito era estimular la reflexión en torno de las expectativas y alternativas de reintegración social, abriendo espacio a la expresión de temores e incertidumbres.

No obstante su carácter secuencial, el planteamiento de la metáfora persiguió propiciar el trabajo elaborativo sin plantearse como un guion rígido que preten- 
diera conducir la comunicación en una determinada dirección. Se trataba más bien de adecuarse a la singularidad de cada caso, del propio proceso elaborativo y de la forma en que cada cual se apropiaba -o no- de la metáfora.

\section{Procedimiento}

La aplicación de la intervención tuvo lugar en dos unidades de la red de atención de CIJ en la Ciudad de México, una de consulta externa y otra de tratamiento residencial. A los interesados se les explicaba en qué consistiría la intervención y que esta sería conducida por una terapeuta externa a la unidad, como parte de la prueba de una alternativa de atención.

La frecuencia de las sesiones varió en función de la disponibilidad de los participantes, a saber, diariamente, cada tercer día o una vez por semana. En un caso, el desarrollo del proceso permitió que la intervención se redujera a dos sesiones, pero en otros dos debió extenderse a cuatro. Todas las sesiones fueron grabadas y transcritas para fines de análisis.

Para la elaboración de la carta terapéutica, la terapeuta recuperaba el material audiograbado y lo plasmaba en una narrativa que perseguía recuperar los momentos del proceso que a su parecer resultaban significativos. El texto era revisado conjuntamente con el segundo de los autores, con el fin de valorar su sensibilidad al proceso y a las características de los participantes. En general, las cartas fueron entregadas a sus destinatarios unos días después de concluida la intervención.

En la última sesión se aplicó una cédula con datos de identificación, sociodemográficos y de uso de sustancias.

\section{Ética}

Se informó a los participantes el objetivo del proyecto y en qué consistiría su participación, los posibles riesgos y beneficios, así como el uso que se daría a la información; a partir de ello se obtuvo su consentimiento escrito. En todo momento se garantizó la confidencialidad y anonimato de la información y se aclaró que una negativa a participar o el consentimiento de seguir participando no afectaría la atención que recibían en CIJ. Igualmente, se solicitó su autorización para grabar las sesiones.

\section{Análisis}

Se efectuó una reconstrucción descriptiva del proceso elaborativo resultante de la aplicación de la intervención. Primero a través de una síntesis transversal de elementos comunes a los casos participantes; segundo, mediante el análisis pormenorizado de un caso (identificado con el seudónimo de Gabriel). Se dirigió la lectura del material en función de los tres momentos de la metáfora, identificando aspectos como definiciones del problema y planteamiento de alternativas, expresión de afectos, resignificación de vínculos, definiciones identitarias, implicación en el tratamiento y expectativas, con especial atención en la producción metafórica a lo largo del proceso.

\section{Resultados}

Al inicio de la intervención la metáfora fue articulada en términos de la partida y de la decisión de haber emprendido el viaje del tratamiento. Los consultantes relataron las circunstancias que los rodeaban, el abatimiento y dificultades que los afligían, la impotencia y frustración que experimentaban ante el consumo incon- 
trolable, la perturbación de la vida familiar, los problemas que no lograban resolver. Igualmente, refirieron los motivos para buscar tratamiento, el cansancio ante la vida vinculada con las drogas, la necesidad de afirmar su capacidad de decisión. Entre los más jóvenes, los relatos versaron acerca de cómo habían podido eludir la autoridad de los padres o maestros, las situaciones que emanaron de ser descubiertos, la intervención de la policía, la vigilancia de los padres y los procesos judiciales. Los jóvenes se cuestionaron si originalmente la búsqueda de tratamiento había sido una decisión propia suponiendo, al contrario, que se habían visto orillados por las circunstancias; no obstante, al avanzar las sesiones, emergió un interés propio por el tratamiento.

Durante la reconstrucción narrativa del tratamiento, del viaje propiamente dicho, se formularon expresiones diversas de deseo de cambio, nuevos cursos de acción posibles y formas alternativas de significar la experiencia. Fue posible identificar la redefinición de condiciones que rodeaban al problema, una nueva ponderación de riesgos, así como la aceptación de dificultades que interferían en sus vidas o de una necesidad de ayuda que antes había sido denegada. Los consultantes también manifestaron su reconocimiento de la mejoría y el cambio, a través por ejemplo de la identificación de habilidades y recursos recientemente adquiridos o recuperados, "una mayor madurez", una nueva "capacidad de decisión", así como una renovada aceptación y revaloración de sí, abonando a una mayor seguridad y autoestima. En un sentido similar, se externalizó la revaloración de vínculos con personas cercanas en el sentido de descubrir, tras una primera impresión de conflicto, el apoyo incondicional de la familia durante el tratamiento.
Fue notoria en esta fase la apropiación de nociones y términos del programa de tratamiento, adaptados de manera sensible a la descripción de circunstancias singulares y con ejemplos concretos de la experiencia de cada consultante. Quizá la experiencia más significativa referida respecto del proceso de tratamiento fue la de sentirse escuchados, aceptados y comprendidos, y no juzgados o etiquetados.

Por lo que se refiere al próximo arribo, al término del tratamiento y a la reinserción social, los relatos apuntaron a lo que podría ser, principalmente constituidos por narrativas de esperanza, alegría, recuperación de vínculos, planes y deseos, aunque también de temores, inquietudes e incertidumbre. Aun cuando en algunos casos los consultantes afirmaran sentirse cansados física y mentalmente, sus relatos reflejaban contento y una visión retrospectiva del tratamiento como algo que había valido la pena. Otros, no obstante, consideraban que su estancia en tratamiento había sido insuficiente y que debería prolongarse; esto fue común a aquellos que participaban en un programa consistente principalmente en actividades psicoeducativas grupales, razón por la cual acusaban la falta de un espacio individual en el que hubieran podido abordar sus problemas personales.

La metáfora del viaje fue adoptada de manera más activa y creativa por los participantes en tratamiento residencial, lo cual puede atribuirse a la separación espacial y temporal de su entorno y, por ende, a una más cercana analogía entre su situación en tratamiento y la idea de una travesía. Los asistentes al centro de consulta externa mantenían, en cambio, sus rutinas habituales, por lo que la idea de una separación les resultaba menos familiar; no obstante, incluso en su caso fue 
posible observar una clara diferenciación del proceso temporal articulado en función de un antes, durante y después del tratamiento.

De esta diferencia de condiciones se desprendió la posibilidad de trabajar, en el caso de la unidad de hospitalización, elementos metafóricos adicionales asociados a la metáfora. Uno de ellos fue la descripción de fotografías imaginarias, ejercicio que permitió situar distintos momentos significativos del proceso. La primera de las fotografías captaba el ingreso a tratamiento; para algunos se trataba de una imagen sepia, en la que se hallaban solos; se describían tristes, sin esperanza ni ilusiones, confundidos y en malas condiciones físicas y anímicas. La segunda coincidía, en un par de casos, con actividades recreativas del propio tratamiento, durante las cuales convivieron y se divirtieron sin drogas. Otro rememoró una demostración deportiva en la unidad, de la que fue elegido como coordinador; en la fotografía se hacía lucir junto a su madre, quien se mostraba orgullosa de él. Las últimas imágenes fueron generalmente de los propios consultantes con sus familias; imágenes coloridas, en días soleados y con personajes sonrientes. Alguien afirmó que su tercera fotografía era una imagen de sí mismo abordando el transporte de regreso a casa, con una sonrisa en el rostro y "dos maletas llenas de ilusiones". Comentaron que las fotos las compartirían con sus familiares o que las colocarían en un sitio a la vista de todos para mostrar cómo, ante momentos difíciles, se puede salir adelante.

No obstante que en general el contenido de las sesiones se articuló en función de los tres momentos del viaje, el despliegue metafórico no se circunscribió necesariamente a esta idea, sino que abarcó otras expresiones como "abrir las puertas", "poner las cosas en balanza", "hacer castillos en el aire", "deshacer la madeja", "echar la carne al asador", "ir de la mano", "poner un grano de arena", "pedir al cuerpo un alto", "una duda que llega a los tuétanos", "cambiar de chip", "armar el rompecabezas propio", "viajar al desierto", "enmascararse con la droga", ser como "el caballero y su armadura", y así sucesivamente. De manera similar, se registraron referencias a objetos metafóricos que condesaban el significado de la experiencia. La metáfora de las maletas, por ejemplo, operó en algunos casos como aquello que daba cabida en la partida a elementos identitarios con los que habían decidido hacer el viaje (ropa, música, objetos personales). Otros depositaron en sus maletas las cosas de las que no se habían hecho responsables, el aliento y apoyo que les había brindado su familia, o bien, los sentimientos "encontrados" y la ambivalencia con que habían ingresado a tratamiento. En la fase del retorno o arribo, el equipaje era en algunos casos más ligero, porque durante el viaje se habían podido expresar emociones y pensamientos acallados, lo que había implicado quitarse "un peso de encima". Otros, al contrario, consideraron que al inicio sus maletas estaban vacías de sentido, de proyectos, de esperanza y que, en cambio, al regreso se sentían más pesadas porque iban llenas de "proyectos, deseos e ilusiones". Otro objeto metafórico, un caleidoscopio, surgió para connotar la experiencia del tratamiento como una experiencia de múltiples cambios y matices.

\section{Gabriel}

Al momento de la intervención, Gabriel estaba a dos semanas de concluir el tratamiento residencial al que había ingresado por consumo de cocaína-crack. Contaba con 33 años, era casado y tenía dos hijas; había cursado estudios profe- 
sionales sin concluirlos y hasta hacía poco había trabajado en una escuela de estudios comerciales -empleo del que había sido despedido- y como personal de seguridad en un bar.

Al inicio, reconoció las dificultades que enfrentaba cuando estaba por decidir ingresar al tratamiento. Pesaba apenas 50 kilos, se sentía mal consigo mismo y con los demás, y temía perder a su familia. Se daba cuenta de que podía "venir algo fuerte", algo que podría tomar el control de su vida de manera negativa, incluso destructiva.

Ante la urgencia de "detener su propia caída", decidió emprender un "viaje" de reencuentro consigo mismo -señaló, haciendo uso del recurso metafórico propuesto-, aunque en aquel entonces no había podido imaginar el "gran cambio que experimentaría". Relató que en sus maletas llevaba a su familia, a su esposa y sus hijas; traía también muchas "ganas" de dejar de sentirse atrapado, humillado y con una "piedra encima"1. También reconoció haberse sentido debilitado, entristecido y desesperado. En este sentido, a pesar de que su llegada a tratamiento no había sido fácil, el agotamiento producido por los problemas que lo aquejaban lo habían motivado a intentar el cambio.

Gabriel decía que había ingresado al tratamiento "desnudo", sin nada, que se había tenido que despojar de prejuicios, de la soberbia, la altanería y el miedo, para permitirse recibir ayuda y cambiar lo que hasta ese momento había creído y pensado de sí y de sus circunstancias. Fue entonces cuando emprendió lo que, a su decir, fue la tarea más ardua e inquietante del viaje: conocerse a sí mismo. Entendió que la raíz de las dificultades que lo afec-

\footnotetext{
${ }^{1}$ Piedra es un nombre popular del crack.
}

taban era diversa y que no podía reducirse al consumo.

En el transcurso del viaje, reconoció que hubo personas que lo acompañaron: su esposa, su madre y varios integrantes de la unidad en que se hallaba internado, por quienes afirmó sentir gratitud y aprecio. Gracias a que sus familiares se involucraron en el tratamiento, pudo reconstruir vínculos, haciéndolos más sólidos y nutricios.

En su decir, el viaje significó una rica experiencia de aprendizaje, le permitió descubrir que sentía, que podía amar, que podía llorar y que eso no implicaba una pérdida de tiempo, sino al contrario, una forma de recuperarse. Incluso, reconoció que a veces se podía permitir sentirse vulnerable, sin que ello le restara valía, ni mermara su capacidad para pensar. De esta manera, Gabriel daba significado a su implicación con el tratamiento y a sus expectativas de recuperación, en términos de cuestionar el discurso que dicta que los hombres deben acallar sus sentimientos.

Gabriel relató cómo había logrado identificar recursos propios -más allá de los aprendidos en el tratamiento- para abstenerse de usar drogas; refirió, por ejemplo, que logró resistirse, incluso ante claras oportunidades de consumo, al pensar en su madre y en su familia. De la misma manera, cuando decidió recurrir al tratamiento, pudo evitar las drogas durante una semana entera antes de ser ingresado. Este reconocimiento de la capacidad propia podía llegar a ser un elemento crucial en el momento del egreso, en virtud de que lo empoderaría para hacer frente a situaciones relacionadas con las drogas por venir.

Comentó Gabriel que después del tiempo que había venido "navegando" había lle- 
gado a entender que "estar en las drogas" era como ver el mundo a través de un tubo y que al deshacerse de él pudo recordar muchas escenas olvidadas y empezar a contemplar otras opciones en su vida. Al término del viaje reencontró lo que había querido conservar: su familia y, sobre todo, a sí mismo y la certeza de que nunca más querría "volver a perderse". En este sentido, señaló que el barco en el que había navegado era sólido.

Para Gabriel el viaje no terminaría cuando concluyera su tratamiento; continuaría viajando, aunque por otros medios. Por lo pronto, a este segmento de su travesía decidió llamarlo "crecimiento" pues -afirmó- a la unidad no había llegado solo para dejar de drogarse, sino para crecer. Admitiendo que el viaje no concluiría con el tratamiento, se proponía continuar el camino apropiándose de nuevas herramientas que le permitirían planificar su vida, sin tener que andar "apagando fuegos". La "materia prima" que se llevaba consigo la utilizaría para "construir cosas buenas", aunque temía que pudieran llegarle a faltar las instrucciones para hacerlo. Trataría de estar atento y no "ponerse el pie", no descuidarse y ser responsable, más flexible y sentir tanto como le fuera posible. Afirmó sentirse feliz con el Gabriel que había encontrado, consciente de que requeriría seguir trabajando, tener presentes los detalles y las pequeñas cosas y, finalmente, tomarse el tiempo para emprender sus proyectos "sin atajos".

Sabía que tendría que afrontar momentos difíciles en el futuro, de la misma manera que había afrontado "tormentas durante el viaje". Situaciones como el crecimiento de sus hijas, posibles conflictos con su esposa, la vejez o la pérdida de su madre. Sabía que no todo sería "color de rosa", pero reconocía que lo más importante era la forma en que haría frente a sus circuns- tancias. Trazarse una imagen del futuro próximo y más distante le permitió situar dificultades, aceptando la necesidad de mantenerse vigilante y de no olvidarse de los recursos adquiridos durante el viaje, durante su propio viaje de autoconocimiento.

Al final, Gabriel reflexionó acerca del día en que el viaje se acercara a su fin; podría entonces sentirse más tranquilo. Sin embargo, no contaba ahora sino con la "materia prima" con la que comenzaría a construir su futuro. Después, su esposa y él disfrutarían de sus logros, cuando sus hijas hubiesen emprendido su propio viaje. En este punto, era de notar un uso patente del subjuntivo como tiempo verbal condicionado, no fáctico, y del futuro anterior como forma propicia para la expresión y la imaginación de lo posible, al plantear cómo podría llegar a sentirse en un cierto futuro después de haber cumplido determinados propósitos.

\section{Discusión y conclusiones}

La revisión del recuento narrativo a partir de la metáfora del tratamiento como viaje, permite destacar ahora algunos elementos relevantes del proceso de reelaboración desplegado durante la intervención. Más allá de los contenidos específicos de los relatos, los cuales dependieron sin duda de las características de los consultantes, se observa en general un proceso elaborativo denso y significativo, así como una similar articulación de los tres momentos lógicos del relato. En este contexto, interesa ahora destacar tres aspectos directamente vinculados con el proceso de elaboración narrativa y cuatro elementos referentes, más bien, a sus implicaciones relacionales y subjetivas.

El primer punto remite al ordenamiento temporal de los relatos, al establecimiento 
de una continuidad secuencial que tanto Bruner (1996) como Sarbin (1986) plantean como componente básico de la lógica narrativa y que Angus y colaboradores han postulado como elemento central del proceso de tratamiento (Angus \& Bouffard-Bowes, 2003; Angus \& Hardtke, 1994; Hardtke \& Angus, 2004). En este sentido, la revisión de casos permite situar a la metáfora como eje que da pauta al recuento narrativo en tres momentos diferenciados: el inicio, el despliegue de episodios y la prefiguración de un próximo desenlace que otorga al relato un determinado sentido de resolución (Angus \& Hardtke, 2007).

En segundo lugar, en la revisión realizada se pueden encontrar diversos ejemplos de cómo el recurso a la metáfora propicia la expresión de afectos como parte de un proceso interno de vinculación de los acontecimientos relatados y su significado afectivo. Un ejemplo de esto es el recuento de experiencias de pérdida o traumáticas, es decir, la pérdida de los hijos o de la madre, cuyas implicaciones afectivas hallan en el relato un espacio para ser trabajados (Etherington, 2007). Cabe recordar, en este contexto, que la intensidad y el tono afectivos han sido identificados como indicadores tanto de la significación subjetiva del relato (Angus \& McLeod, 2004) como de la calidad de la relación terapéutica (Goldin, 2008), al tiempo que una investidura afectiva que no resulta desbordante ni estereotipada opera como marca distintiva del trabajo elaborativo efectuado (Angus \& Hardtke, 2007).

El tercer punto que interesa subrayar comprende la integración reflexiva de la experiencia que apunta a la conformación de una narrativa coherente e integrada capaz de conferirle sentido, orientación y propósito (Angus \& McLeod, 2004; Salvatore et al., 2006; Strickland, 1994). El propio proceso de cura y de reintegración social se han vinculado con esta dimensión reflexiva e integrativa de la narración (Hänninen \& Koski-Jännes, 2004; Ramírez-Esparza \& Pennebaker, 2006; Singer et al., 2013). Acorde con esto, en los casos revisados es posible constatar la emergencia de expresiones diversas de reflexión e interpretación del curso de los acontecimientos, las cuales reflejan una mayor capacidad introspectiva y de conexión con el significado global de la experiencia, acompañada de un mayor sentido de coherencia personal (McLean \& Fournier, 2008).

Asimismo, se puede observar nuevamente que el recurso de la metáfora juega un papel relevante, operando como organizador de la estructura global de la experiencia. $\mathrm{La}$ metáfora guía, en efecto, en una amplia medida, la selección y ordenamiento de acontecimientos, la expresión de circunstancias y afectos y, en última instancia, la configuración, a la vez sintética y compleja, del significado y orientación de la experiencia (Angus \& Hardtke, 2007; Shinebourne \& Smith, 2010). La abundancia de metáforas y otros recursos expresivos confirma, así, su lugar central en el proceso terapéutico (Shinebourne \& Smith, 2010; Wirtztum et al., 1988).

Por su parte, las cartas elaboradas inicialmente como un medio para constatar la escucha y promover la internalización del diálogo terapéutico, también contribuyeron a fortalecer el efecto integrativo de la intervención, ofreciendo a los consultantes un recurso adicional para la reflexión respecto del sentido global de su experiencia.

Por lo que se refiere a otras implicaciones relacionales y subjetivas de la intervención, se puede recalcar, primero, cómo la aceptación y acogida de los consultantes, 
lo mismo que el ejercicio de una escucha empática, contribuyeron a generar condiciones de seguridad y confianza que facilitaron un intercambio psicológicamente significativo. A partir de esto, la propia articulación cognitivo-afectiva de la experiencia puede haber contribuido a fortalecer la alianza terapéutica (Angus \& McLeod, 2004; Goldin, 2008; von Braun et al., 2013).

Correlativamente, puede ser que la articulación narrativa a partir de la metáfora del viaje haya proporcionado un anclaje social a la experiencia de los consultantes (Singer \& Rexhaj, 2006). Ello sería atribuible al significado y pertinencia cultural de la propia noción de viaje, en tanto experiencia liminar de reestructuración de la imagen de sí y de los marcos normativos de la existencia, acompañada de sentimientos de renovación y crecimiento, pero igualmente de incertidumbre y ambivalencia (Smelser, 2009). En este sentido, es posible que el recuento narrativo haya remitido a esquemas discursivos $\mathrm{y}$ semánticos provenientes de un marco sociocultural compartido (Polkinghorne, 2004), lo cual habría de abonar a la significación social de la experiencia personal y al sentido de pertenencia. Según Giuliani (2013), esto contribuiría a resolver las "fracturas narrativas" asociadas al uso de sustancias.

En una dirección similar, un par de consultantes resaltaron la importancia de la estructura proporcionada por el tratamiento, aludiendo a la lógica de un proceso de transición en el que ya no se es adicto, pero tampoco se ha dejado de serlo y hay, por ende, la necesidad de confiarse al sistema terapéutico para atravesar el proceso de reconfiguración identitaria, lo cual hace resonancia con algunos atributos de las terapias de inclusión descritas por Epston y White (1992).
Otro aspecto digno de mención es la construcción de una mayor agencia personal, de una mayor autonomía y sentido de autoría en la confección de la propia historia (Angus \& Hardtke, 2007; Ramírez-Esparza \& Pennebaker, 2006). En particular, la intervención representó una oportunidad para configurar una diferente percepción de sí, en un proceso de incipiente transformación y reapropiación identitaria a través del cual algunos lograron situarse más allá de una identidad signada por las drogas (Duero \& Limón Arce, 2007; Etherington, 2006; Garzón \& Riveros, 2012; Koski-Jännes, 2002; McIntosh \& McKeganey, 2001). Se trata de la llamada "migración identitaria" que lleva a aprehender la recuperación como un proceso de resignificación del lugar de etiquetamiento y exclusión atribuido y asumido por los consultantes (White, 2002; White \& Epston, 1993).

En este sentido, la posición de hospitalidad y aceptación de la diferencia que se recoge de Anderson (1997, 2001), Anderson y Goolishian (1992), Fernández (2013) y Shotter (2005), permitió en algunos casos allanar el camino para la revisión de esquemas cristalizados que convergían en la reproducción de problemas y daban sostén al sometimiento a distintas formas de ejercicio del poder, incluso al interior del propio espacio terapéutico. Como se ha señalado, el carácter propiamente político de este ejercicio deconstructivo, ha sido particularmente subrayado por Brown (2007) y Sanders (1998, 2007). De esta manera, la propuesta de un encuentro basado en la reciprocidad y el reconocimiento mutuo (Gergen, 2007; McNamee, 2009; McNamee \& Gergen, 1992) se contrapone a los enfoques dominantes en el abordaje terapéutico del uso de sustancias que definen el lugar del terapeuta en términos de "conocimiento experto" y reducen la intervención a la aplicación de tecnologías 
(re)adaptativas que invisibilizan la construcción social del problema (Kaplan, 1982; Sanders, 1998, 2007).

Por último, a pesar de que un relato integrado supone una cierta resolución, esto no implica que no se abra a posiciones subjetivas y significados emergentes, o que no explore la multiplicidad de voces, circunstancias y matices que suelen resonar en su trama (Anderson, 2005; Angus \& McLeod, 2004; McLean \& Fournier, 2008; Singer \& Rexhaj, 2006). En este sentido, la densidad de los relatos, su abundante e instanciado contenido asociativo, pueden dar cuenta del intenso trabajo elaborativo al que pudo llevar la metáfora como recurso abierto a la reinvención del sentido. Por esta vía, se dio paso a configuraciones emergentes de sentido y al esbozo de posibles alternativas de existencia que, si bien pudieron implicar una mayor incertidumbre y contingencia, finalmente, posibilitaron, en opinión de los autores, la historización de lo acontecido (Fernández, 2013) y una anticipación significativa del futuro inmediato.

En una dirección similar, las cartas terapéuticas apuntalaron la desconstrucción de nociones naturalizadas, retomando propuestas como la externalización, la dilucidación de trampas y las predicciones del futuro próximo (Callahan, 2001; Man-Kwong, 2004; Sanders, 1998, 2007; White \& Epston, 1993), que permitieron someter a revisión categorías naturalizadas como las recaídas o las adicciones como enfermedad incurable para proponer, en cambio, el análisis de la relación que los consultantes mantenían con las drogas.

Para concluir, cabe señalar que el presente trabajo da cuenta del proceso de elaboración e integración narrativa de la experiencia de una manera global y descriptiva. No obstante que esto impide que los resultados puedan generalizarse con base en los criterios inductivo-deductivos habituales; es posible postular una validación discursiva, dialógica y construccionista, en la medida en que el esfuerzo narrativo efectuado por los consultantes constituye un ejercicio interpretante inserto en un contexto discursivo compartido. En esta medida, abonan a la validez de los hallazgos criterios como credibilidad, verosimilitud, potencial explicativo, recurrencia, consistencia teórica y congruencia interna.

Sin embargo, se reconoce la conveniencia de ampliar el análisis mediante un abordaje sistemático del proceso de ajuste narrativo a lo largo de la intervención incorporando, por ejemplo, el examen de marcadores discursivos o de contenidos específicos. De igual modo, determinar la efectividad de la intervención requeriría introducir grupos de comparación y la aplicación de mediciones que permitieran evaluarla a través de variables como adherencia terapéutica y bienestar afectivo, entre otros. Por último, evaluar su eficacia en términos de abstinencia y reintegración social requeriría un seguimiento longitudinal y prospectivo.

\section{Referencias}

Anderson, H. (1997). Conversación, lenguaje y posibilidad. Un enfoque posmoderno de la terapia. Buenos Aires: Amorrortu Editores.

Anderson, H. (2001). Ethics and uncertainty: Brief unfinished thoughts. Journal of Systemic Therapies, 20(4), 3-6.

http://dx.doi.org/10.1521/jsyt.20.4.3.23083 
Anderson, H. (2005). Un enfoque posmoderno de la terapia: la música polifónica y la terapia "desde dentro". En G. Limón Arce (Comp.), Terapias posmodernas, aportaciones construccionistas (pp. 59-67). México: Pax.

Anderson, H. \& Goolishian, H. (1992). El experto es el cliente: la ignorancia como enfoque terapéutico. En S. McNamee \& K. Gergen (Coords.). La terapia como construcción social (pp. 45-59). Barcelona: Paidós.

Angus, L. \& Bouffard-Bowes, B. (2003). "No lo entiendo": la búsqueda de sentido emocional y coherencia personal ante una pérdida traumática durante la infancia. Revista de Psicoterapia, 12(49), 25-46.

Angus, L. \& Hardtke, K. (1994). Narrative processes in psychotherapy. Canadian Psychology, 35(2), 190-203.

http://dx.doi.org/10.1037/0708-5591.35.2.190

Angus, L. \& Hardtke, K. (2007). Margaret's story: An intensive case analysis of insight and narrative process change in client-centered psychotherapy. En L. Castonguay \& C. Hill (Eds.), Insight in psychotherapy (pp. 187-205). Washington, DC: American Psychological Association.

http://dx.doi.org/10.1037/11532-009

Angus, L. \& McLeod, J. (2004). Toward an integrative framework for understanding the role of narrative in the psychotherapy process. En L. Angus \& J. McLeod (Eds.), The handbook of narrative and psychotherapy, practice, theory, and research (pp. 367-374). Thousand Oaks: Sage.

http://dx.doi.org/10.4135/9781412973496.d27

Brown, C. (2007). Situating knowledge and power in the therapeutic alliance. En C. Brown \& T. Augusta-Scott (Eds.), Narrative therapy. Making meaning, making lives (pp. 3-22). Thousand Oaks: Sage.

http://dx.doi.org/10.4135/9781452225869.n1

Bruner, J. (1996). Realidad mental y mundos posibles. Los actos de la imaginación que dan sentido a la experiencia. Barcelona: Gedisa.

Callahan, T. (2001). Alcohol, drugs and suffering. Dulwich Centre Journal, 3-4, 1-8. Recuperado de http://is.gd/zhjV2A

Diamond, J. (2002). Narrative means to sober ends, treating addiction and its aftermath. New York: The Guilford Press.

Díaz Negrete, D. B., Gracia Gutiérrez de Velasco, S. E., \& Fernández Cáceres, C. (2015). Terapia narrativa, una alternativa para el tratamiento del uso de drogas. Revista Electrónica de Psicología Iztacala, 18(4), 1539-1569.

Duero, D. G. \& Limón Arce, G. (2007). Relato autobiográfico e identidad personal: un modelo de análisis narrativo. AIBR: Revista de Antropología Iberoamericana, 2(2), 232-275. http://dx.doi.org/10.11156/aibr.020205 
Epston, D. \& White, M. (1992). Consulting your consultants: The documentation of alternative knowledge. En D. Epston \& M. White (Comps.), Experience, contradiction narrative and imagination (pp. 11-26). Adelaide: Dulwich Centre Publications.

Etherington, K. (2006). Understanding drug misuse and changing identities: A life story approach. Drugs: Education, Prevention and Policy, 13(3), 233-245.

http://dx.doi.org/10.1080/09687630500537555

Eherington, K. (2007). Loss and trauma in the lives of people with a history of drug abuse. Journal of Loss and Trauma, 12(1), 59-72.

http://dx.doi.org/10.1080/15325020600785988

Fernández, A. M. (2013). Jóvenes de vidas grises: psicoanálisis y biopolítica. Buenos Aires: Nueva Visión.

Garzón, D. I. \& Riveros, M. C. (2012). Procesos narrativos conversacionales en la construcción de la identidad del joven y la familia con problemas de consumo de sustancias psicoactivas en una institución de rehabilitación. Psicogente, 15(28), 385-413.

Gergen, K. (2007). La autonarración en la vida social. En A. M. Estrada, S. Diazgranados, \& K. Gergen (Trads. y Comps.), Construccionismo social, aportes para el debate y la práctica (pp. 153-188). Bogotá: Universidad de los Andes, Facultad de Ciencias Sociales, Departamento de Psicología, Centro de Estudios Socioculturales e Internacionales.

Gergen, K. \& Gergen, M. (1986). Narrative form and the construction of psychological science. En T. Sarbin (Ed.), Narrative psychology, the storied nature of human conduct (pp. 22-44). Westport: Praeger.

Giuliani, M. (noviembre, 2013). La pareja tóxicodependiente y la comunidad (la encrucijada de historias). Trabajo presentado en el $15^{\circ}$ Congreso Internacional de Centros de Integración Juvenil. Políticas públicas para la atención de las adicciones, Cancún, México.

Goldin, D. (2008). Tone as a measure of the relationship in psychotherapy and other conarrative experiences. International Journal of Psychoanalytic Self Psychology, 3, 65-83. http://dx.doi.org/10.1080/15551020701721960

Hänninen, V. \& Koski-Jännes, A. (2004). Stories of attempts to recover from addiction. En P. Rosenqvist, J. Blomqvist, A. Koski-Jännes, \& L. Öjesjö (Eds.), Addiction and life course (pp. 231-246). Helsinki: Nordic Council for Alcohol and Drug Research.

Hardtke, K. \& Angus, L. (2004). The narrative assessment interview: Assessing self-change in psychotherapy. En L. Angus \& J. McLeod (Eds.), The handbook of narrative and psychotherapy, practice, theory and research (pp. 247-262). Thousand Oaks: Sage.

Hegarty, T., Smith, G., \& Hammersley, M. (2010). Crossing the river: A metaphor for separation, liminality, and reincorporation. The International Journal of Narrative Therapy and Community Work, 2, 51-58.

Kaplan, Ch. (1982). Addict life stories: An exploration of the methodological grounds for the study of social problems. International Journal of Oral History, 3(1), 31-50.

Koski-Jännes, A. (2002). Social and personal identity projects in the recovery from addictive behaviours. Addiction Research and Theory, 10(2), 183-202.

http://dx.doi.org/10.1080/16066350290017266 
Kvale, S. (1999). Psychology and postmodernism. London: Sage.

Lakoff, G. \& Johnson, M. (1995). Metáforas de la vida cotidiana. Madrid: Cátedra.

Man-Kwong, H. (2004). Overcoming craving: The use of narrative practices in breaking drug habits. The International Journal of Narrative Therapy and Community, 1, 17-24.

McIntosh, J. \& McKeganey, N. (2001). Identity and recovery from dependent drug use, the addict's perspective. Drugs: Education, Prevention and Policy, 8(1), 47-59.

http://dx.doi.org/10.1080/09687630124064

McLean, K. (2008). Stories of the young and the old: Personal continuity and narrative identity. Developmental Psychology, 44(1), 254-264.

http://dx.doi.org/10.1037/0012-1649.44.1.254

McLean, K. \& Fournier, M. (2008). The content and processes of autobiographical reasoning in narrative identity. Journal of Research in Personality, 42(3), 527-545.

http://dx.doi.org/10.1016/j.jrp.2007.08.003

McLean, K., Pasupathi, M., \& Pals, J. (2007). Selves creating stories creating selves: A process model of self-development. Personality and Social Psychology Review, 11(3), 262-278.

http://dx.doi.org/10.1177/1088868307301034

McNamee, S. \& Gergen, K. J. (1992). La terapia como construcción social. Barcelona: Paidós.

McNamee, S. (2009). Postmodern psychotherapeutic ethics, relational responsibility in practice. Human Systems: The Journal of Therapy, Consultation \& Training, 20(1), 57-71.

Mikkonen, K. (2007). The "narrative is travel" metaphor: Between spatial sequence and open consequence. Narrative, 15(3), 286-305.

http://dx.doi.org/10.1353/nar.2007.0017

Polkinghorne, D. (2004). Narrative therapy and postmodernism. En L. Angus \& J. McLeod (Eds.), The handbook of narrative and psychotherapy, practice, theory, and research (pp. 52-67). Thousand Oaks: Sage.

http://dx.doi.org/10.4135/9781412973496.d5

Ramírez-Esparza, N. \& Pennebaker, J. (2006). Do good stories produce good health? Exploring words, language, and culture. Narrative Inquiry, 16(1), 211-219.

http://dx.doi.org/10.1075/ni.16.1.26ram

Ricoeur, P. (2003). Teoría de la interpretación. Madrid: Siglo XXI Editores.

Salvatore, G., Conti, L., Fiore, D., Carcione, A., DiMaggio, G., \& Semerari, A. (2006). Disorganized narratives: Problems in treatment and therapist intervention hierarchy. Journal of Constructivist Psychology, 19(2), 191-207.

http://dx.doi.org/10.1080/10720530500508936

Sanders, C. J. (1998). Substance misuse dilemmas: A postmodern inquiry. En S. Madigan \& I. Law (Eds.), Praxis: Situating discourse, feminism and politics in narrative therapies (pp. 143-162). Vancouver: Yaletown Family Therapy Press. 
Sanders, C. J. (2007). A poetics of resistance, compassionate practice in substance misuse therapy. En C. Brown \& T. Augusta-Scott (Eds.), Narrative Therapy. Making meaning, making lives (pp. 59-76). Thousand Oaks: Sage.

http://dx.doi.org/10.4135/9781452225869.n4

Sarbin, T. (1986). The narrative as a root metaphor for psychology. En T. Sarbin (Ed.), Narrative psychology, the storied nature of human conduct (pp. 3-21). Westport: Praeger.

Shinebourne, P. \& Smith, J. A. (2010). The communicative power of metaphors: An analysis and interpretation of metaphors in accounts of the experience of addiction. Psychology and Psychotherapy: Theory, Research and Practice, 83(1), 59-73.

http://dx.doi.org/10.1348/147608309x468077

Shotter, J. (2005). Acknowledging unique others: Ethics, "expressive realism," and social constructionism. Journal of Constructivist Psychology, 18(2), 103-130.

http://dx.doi.org/10.1080/10720530590914761

Singer, J. \& Bluck S. (2001). New perspectives on autobiographical memory: The integration of narrative processing and autobiographical reasoning. Review of General Psychology, 5(2), 91-99.

http://dx.doi.org/10.1037//1089-2680.5.2.91

Singer, J. \& Rexhaj, B. (2006). Narrative coherence and psychotherapy: A commentary. Journal of Constructivist Psychology, 19(2), 209-217.

http://dx.doi.org/10.1080/10720530500508944

Singer, J., Singer, B., \& Berry, M. (2013). A meaning-based intervention for addiction: Using narrative therapy and mindfulness to treat alcohol abuse. En J. A. Hicks \& C. Routledge (Eds.), The experience of meaning in life: Classical perspectives, emerging themes, and controversies (pp. 379-391). New York: Springer.

http://dx.doi.org/10.1007/978-94-007-6527-6_28

Smelser, N. (2009). The Odyssey experience: Physical, social, psychological, and spiritual journeys. Berkeley: University of California Press.

http://dx.doi.org/10.1525/california/9780520258976.001.0001

Strickland, L. (1994). Autobiographical interviewing and narrative analysis: An approach to psychosocial assessment. Clinical Social Work Journal, 22(1), 27-41. http://dx.doi.org/10.1007/bf02190284

Tay, D. (2011). Therapy is a journey as a discourse metaphor. Discourse Studies, 13(1), 47-68. http://dx.doi.org/10.1177/1461445610387736

von Braun, T., Larsson, S., \& Sjöblom, Y. (2013). Narratives of clients' experiences of drug use and treatment of substance use-related dependency. Substance Use \& Misuse, 48(13), 1404-1415.

http://dx.doi.org/10.3109/10826084.2013.817148

White, M. (2002). Reescribir la vida. Entrevistas y ensayos. Barcelona: Gedisa.

White, M. (2007). Maps of narrative practice. New York: W.W. Norton \& Company.

White, M. \& Epston, D. (1993). Medios narrativos para fines terapéuticos. Barcelona: Paidós. 
Wirtztum, E., van der Hart, O., \& Friedman, B. (1988). The use of metaphor in psychotherapy. Journal of Contemporary Psychotherapy, 18(4), 270-290.

Fecha de recepción: 9 de abril de 2015

Fecha de aceptación: 18 de agosto de 2015 